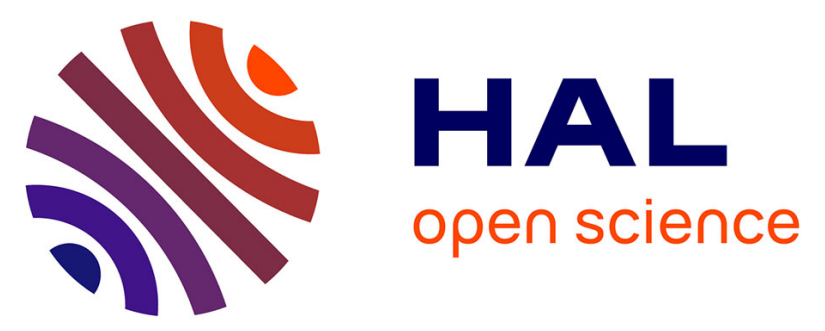

\title{
IDIOPATHIC INTRACRANIAL HYPERTENSION: GLYMPHOEDEMA OF THE BRAIN
}

Patrick Nicholson, Alice Kedra, Eimad Shotar, Sophie Bonnin, Anne-Laure L Boch, Natalia Shor, Frédéric Clarençon, Valérie Touitou, Stephanie Lenck

\section{- To cite this version:}

Patrick Nicholson, Alice Kedra, Eimad Shotar, Sophie Bonnin, Anne-Laure L Boch, et al.. IDIOPATHIC INTRACRANIAL HYPERTENSION: GLYMPHOEDEMA OF THE BRAIN. Journal of Neuro-Ophthalmology, 2021, 41 (1), pp.93-97. 10.1097/WNO.0000000000001000 . hal-03261420

\section{HAL Id: hal-03261420 \\ https: / hal.sorbonne-universite.fr/hal-03261420}

Submitted on 15 Jun 2021

HAL is a multi-disciplinary open access archive for the deposit and dissemination of scientific research documents, whether they are published or not. The documents may come from teaching and research institutions in France or abroad, or from public or private research centers.
L'archive ouverte pluridisciplinaire HAL, est destinée au dépôt et à la diffusion de documents scientifiques de niveau recherche, publiés ou non, émanant des établissements d'enseignement et de recherche français ou étrangers, des laboratoires publics ou privés. 
IDIOPATHIC INTRACRANIAL HYPERTENSION: GLYMPHOEDEMA OF THE

\section{BRAIN}

P. Nicholson MD ${ }^{1}$, A. Kedra MD ${ }^{2}$, E. Shotar $\mathrm{MD}^{2}, \mathrm{~S}$. Bonnin $\mathrm{MD}^{3}$, AL. Boch MD ${ }^{4}, \mathrm{~N}$.

Shor $\mathrm{MD}^{2}$, F. Clarençon MD, $\mathrm{PhD}^{2}$, V. Touitou MD $\mathrm{PhD}^{3}$, S. Lenck MD ${ }^{2}$

${ }^{1}$ Department of Neuroradiology, Toronto Western Hospital, Toronto, Canada

${ }^{2}$ Department of Neuroradiology, Groupe Hospitalier Pitié Salpêtrière, Paris, France

${ }^{3}$ Department of Ophthalmology, Groupe Hospitalier Pitié Salpêtrière, Paris, France

${ }^{4}$ Department of Neurosurgery, Groupe Hospitalier Pitié Salpêtrière, Paris, France

Running title: IIH: brain glymphoedema

\section{Corresponding author:}

Dr Stéphanie Lenck

Service de Neuroradiologie, Bâtiment Babinski, Groupe Hospitalier Pitié Salpêtrière, 47-83

Boulevard de l'Hôpital, 75013 Paris.

Email Address: stephanie.lenck@orange.fr

Phone number: $+33(0) 142163531$

The authors report no disclosures, and no conflict of interest

Keywords: Idiopathic Intracranial Hypertension, Glymphatic system, venous stenoses,

Lymphatic system 


\section{ABSTRACT}

Background : During the last decade, our understanding of cerebrospinal fluid (CSF) physiology has dramatically improved thanks to the discoveries of both the glymphatic system and of lymphatic vessels lining the dura mater in human brains.

Evidence acquisition : We detail the recent basic science findings in the field of CSF physiology and connect them with our current understanding of the pathophysiology of idiopathic intracranial hypertension (IIH).

Results : Transverse sinus stenoses appear to play a major causative role in the symptoms of $\mathrm{IIH}$, as a result of a decrease in the pressure gradient between the venous system and the subarachnoid space. However, the intracranial pressure (ICP) can be highly variable amongst different patients, depending on the efficiency of the lymphatic system to resorb the CSF as well as on the severity of transverse sinus stenoses. It is likely that there is a sub-clinical form of IIH and that IIH without papilledema is probably under-diagnosed among patients with chronic migraines or isolated tinnitus.

Conclusions : IIH can be summarized in the following pathological triad: Restriction of the venous CSF outflow pathway - Overflow of the lymphatic CSF outflow pathway - Congestion of the glymphatic system. In order to better encompass all the stages of $\mathrm{IIH}$, it is likely that the Dandy's criteria need to be updated, and that perhaps renaming IIH should be considered. 


\section{BACKGROUND}

During the last decade, our understanding of cerebrospinal fluid (CSF) physiology has dramatically improved thanks to the discoveries of both the glymphatic system and of lymphatic vessels lining the dura mater in human brains. While the characterization of CSF physiology is probably one of the most challenging projects in neuroscience, it is likely that these recent (and future) findings will have major clinical implications. The CSF circulation and the cerebrovascular system (including arteries, veins and lymphatics) seem to be more intimately related than previously suspected. Given ongoing work in this area, it is likely that our understanding of the overall picture will probably evolve further in the near future. In particular, it is likely that we will gain a better understanding of the clinical and radiological features of idiopathic intracranial hypertension (IIH) in the broader context of these basic science findings $[1,2]$. This, in turn, will probably lead to significant clinical and therapeutic advances. In this paper, we detail the recent basic science findings in the field of CSF physiology and connect them with our current understanding of the pathophysiology of IIH.

\section{EVIDENCE ACQUISITION}

\section{- The Glymphatic System}

In 2012, Iliff et al. identified the glymphatic system as "a brain-wide pathway for fluid transport, which includes the para-arterial influx of subarachnoid CSF into the brain interstitium, followed by the clearance of interstitial fluid along large-caliber draining veins" [3]. This process is preferentially activated during sleep[4], and is driven by a combination of arterial pulsatility, respiration, and pressure gradients $[5,6]$. The exchange of water molecules between the three compartments of the brain (i.e. the blood, the CSF and the brain parenchyma) is mediated by water-channel transporters called Aquaporins (AQP). 
CSF is continuously produced by the choroid plexuses, which are expansions of the ependymal epithelium in the ventricles [7]. The total constant volume is $150-160 \mathrm{~mL}$ in humans, and this volume is renewed approximately four times per day [8]. CSF production is mediated by osmotic- and pressure-gradients that drive the movement of water and ions from the blood to the ventricular lumen [4]. The exchange of water molecules from the blood to CSF is mediated by AQP-1, which is located in the apical membrane of the choroid plexus epithelial cells [9]. From the ventricles, the CSF then exits through the foramina of Magendie and Monro to reach the subarachnoid space [4]. Alternatively, CSF may exit the ventricles via trans-ependymal spread to reach the perivascular spaces of the brain. This trans-ependymal spread pathway is especially apparent during cases of obstructive hydrocephalous. From the subarachnoid spaces, CSF then enters the periarterial spaces, travelling from the cortex toward the deep white matter along the courses of the pial and perforator arteries [4]. Along with other metabolites, CSF is then filtered and driven from the periarterial space to the brain parenchyma[4]. The transport of water from CSF to the brain is mediated by another watertransporter, AQP-4 [3]. This water channel is expressed in astrocytic endfeet that ensheathe the brain vasculature [3]. This continuous movement of CSF from the periarterial space into the brain parenchyma then drives convective bulk parenchymal fluid flow toward the perivenous spaces surrounding the large cortical veins [3]. Following this, the method of resorption of CSF from the perivenous spaces is still unclear. Two CSF outflow pathways have been described in humans: the venous outflow pathway and the lymphatic outflow pathway.

\section{- CSF outflow}

While the venous CSF outflow pathway has historically been considered as the only way of resorption of CSF, the recent discovery of the dural lymphatics in humans (as distinct from 
the brain parenchymal glymphatic system outlined above) has been another major paradigm shift[10]. In order to better describe the CSF outflow pathways, we first need to clearly distinguish two physiological roles of CSF: a mechanical role (which plays a role in the regulation of ICP), and a metabolic one (which plays a role in clearance of brain metabolites).

- The venous CSF outflow pathway

It was historically believed that the venous resorption of the CSF occurs across the arachnoid villi and granulations. These anatomical structures are traditionally described as focal areas of protrusion of the subarachnoid space across the dura matter into the lumen of the dural sinuses. These "avascular granulations" also play a mechanical role of regulation of the ICP, as the flow of CSF across the granulation is dependent on the pressure gradient between the subarachnoid space and the venous blood of the dural sinus. In the light of the recent scientific findings concerning the glymphatic system, it seems that another type of granulations - the so-called "vascular granulation" - has probably been wrongly neglected over time. Previous pathological [11,12] and radiological studies [12,13], support that some arachnoid granulations may enter the dura mater to reach the lumen of the venous sinuses in close association with a major cortical vein. These "vascular granulations" could represent an anatomical and physiological connection between the perivenous space (draining the ISF from the glymphatic system) and the venous blood of the dural sinus [12]. Vascular granulations may therefore be involved in the excretion of the brain metabolites as one final exit pathway of the glymphatic system. The intrinsic molecular mechanisms of this filtration are however still unknown.

- The lymphatic CSF outflow pathway

It was long believed that the CNS did not have a lymphatic drainage system. Ironically, an Italian anatomist called Paola Mascagni described meningeal-related lymphatic vessels in a 
landmark anatomical text in 1787 , but her findings were discounted by the scientific community for more than 200 years[14]. In 2015, the presence of functional lymphatic vessels lining the dural sinuses was eventually demonstrated in murine brains $[15,16]$. Two years later, Absinta et al went on to image these dural/meningeal lymphatics in both primates and humans [17]. They also seem to be involved in the clearance of the CSF (or ISF) from the glymphatic system[15,18], and also in the regulation of the ICP (through a direct reabsorption of the CSF from the subarachnoid space) [16]. Other work by Hoon Ahn et al, showed that CSF drains preferentially through a basal outflow pathway, with CSF tracers draining via skull base meningeal lymphatics to the deep cervical lymph node system. Anatomically, the lymphatic system of the brain could therefore be described as a drainage network extending from the dural sinuses to both eyes, tracking above the olfactory bulb, following the dural arteries and veins into the dura matter $[15,16]$. The dural lymphatics finally join the skull base, discharging the CSF into the sheaths of the cranial nerves. The CSF is eventually excreted into the deep cervical lymph nodes and the systemic lymphatic circulation [19].

\section{RESULTS}

In the light of these scientific findings, the radiological signs of IIH can be summarized in the following pathological triad (Fig. 1) [1]:

$1 /$ Congestion of the glymphatic system

2/ Overflow of the lymphatic CSF outflow pathway

3/ Restriction of the venous CSF outflow pathway

\section{- IIH: congestion of the glymphatic system}


Several radiological studies indicate that IIH is associated with an increase in CSF in the perivascular spaces of the brain and in the subarachnoid space, suggesting a congestion of the glymphatic system. Since the skull represents a fixed volume, the excess of CSF in the glymphatic system results in increased intracranial pressure. The first radiological observations of IIH were based on CT-scans and showed a reduction of ventricular size, suggesting that IIH was due to cerebral swelling [20]. This interstitial edema was confirmed later with MRI diffusion techniques and with 3D-volumetric MRI sequences [21]. Alperin et al. showed a significant increase in extra-ventricular CSF and interstitial fluid volumes in patients with IIH, when compared to a matched cohort of patients without IIH.

\section{- IIH: overflow of the lymphatic CSF outflow pathway}

Imaging evidence of excess CSF along the sheaths of cranial nerves is one of the cardinal signs of IIH. Most typically this is found along the optic nerve sheaths, however the sheaths of other cranial nerves can also be enlarged. This may be a consequence of the accumulation of CSF along the sheaths of the cranial nerves. This excess of CSF appears to be related to the engorgement of the lymphatic CSF outflow pathway[22,23]. For example, erosion of the cribriform plate (which may result in idiopathic CSF leak) may be the consequence of the chronic overflow of CSF around the olfactory bulbs [24]. Other cardinal imaging signs of IIH are also likely related to an excess of CSF along the relevant nerve sheaths. These imaging signs include widening of the foramen ovale and Meckel's cave dilatation (CSF excess in the trigeminal nerve sheaths), enlargement of the third cranial nerve sheaths in the cavernous sinus [25], [26] and enlargement of Dorello's canal (indicating excess CSF in along the sheaths of CN VI). Finally, meningoceles of the temporal bone, mostly located at the petrous apex or Meckel's cave near the continuation of the nerve sheaths of the acoustic and facial 
nerves also point to an excess of CSF along these nerves. These can also lead to CSF leaks [27].

\section{- Restriction of the venous CSF outflow pathway}

More than $90 \%$ of patients with IIH have transverse sinus (TS) stenoses, which are usually located bilaterally at the junction between the vein of Labbé and the transverse sinus [28]. Those stenoses can result in increased cerebral venous pressure (CVP), leading in turn to a less efficient venous CSF outflow pathway as a result of equalization of the pressure gradient between the subarachnoid space and the venous blood of the dural sinuses. Although TS stenoses are probably the main precipitating factor in the occurrence of clinical symptoms in $\mathrm{IIH}$ - and the resolution of symptoms after venous stenting gives support to this hypothesis the cause of these stenoses remains unclear. However, it is likely that a molecular impairment of CSF filtration at the venodural junction may be responsible for the formation of TS stenoses. We presume that the metabolic and hormonal factors associated with IIH (obesity, hormons, drugs...) may be involved in this molecular trigger.

Two types of venous sinus stenoses have been described in IIH: intrinsic and extrinsic [29]. An intrinsic stenosis can be defined radiologically as a short-segment stenosis secondary to the presence of a sub-arachnoid granulation inside the sinus[30]. Conversely, an extrinsic stenosis can be defined as a long-segment sinus stenosis without an endoluminal abnormality. Patients with intrinsic stenoses are often older than patients with extrinsic stenoses [29]. In patients with intrinsic stenoses, the efficiency of the venous blood-CSF barrier can be impaired as outlined above. Paradoxically, the initial development of an arachnoid granulation may initially slightly delay the manifestation of IIH by increasing the exchange area between the CSF and the venous system. The lymphatic outflow pathway may also initially compensate for the decreased efficiency of the venous CSF pathway. However, as it 
enlarges the arachnoid granulation can eventually cause a mechanical obstruction in the venous sinus which will then lead to increased pressure in the dural sinuses, and thus to IIH symptoms as a result in impairment of the CSF venous outflow pathway.

Extrinsic stenoses on the other hand affect younger patients than intrinsic stenoses. Two mechanisms may be involved in their formation. The first one is a direct compression of the transverse sinus by the congested brain and CSF, suggesting that intracranial hypertension is the cause of LS stenoses. This theory is supported by the disappearance of such extrinsic stenoses after removal of CSF [31], and by their propensity to reform adjacent to the stented zone after stenting [32]. De Simone et al. have hypothesized that the dural sinuses in IIH are hyper-collapsible, to try to explain the mechanism of formation of extrinsic stenoses [33].

\section{CONCLUSIONS}

Transverse sinus stenoses appear to play a major causative role in the symptoms of IIH. The suppression of the pressure gradient between the venous system and the subarachnoid space can in turn lead to further inefficiency of the already impaired venous outflow pathway. Thus, the lymphatic outflow pathway becomes the only CSF outflow pathway of the brain, and the overflow of the CSF along the sheaths of the cranial nerves results in the classical clinical and radiological signs of IIH. The ICP may be highly variable amongst different patients, depending on the efficiency of the lymphatic system to resorb the CSF as well as on the severity of TS stenoses. This may explain why the radiological signs of IIH are frequently found in patients with chronic headache or isolated pulsatile tinnitus without papilledema or raised intracranial pressure. It is likely that there is a sub-clinical form of IIH in these patients, i.e. in patients with a degree of CSF outflow impairment but in whom the signs and symptoms do not yet meet the criteria for IIH. It is therefore likely that IIH without papilledema (IIWOP), (i.e. with normal or near-normal ICP) is probably under-diagnosed among patients 
with chronic migraines or isolated tinnitus [34]. We suggest including the radiological signs in the next revision of the diagnostic criteria of IIH while putting less value on the ICP value. This may be helpful to try and better capture the benign stages of this radio-clinical syndrome. Papilledema and raised intracranial pressure could probably therefore be considered as the most severe stage of the disease, while headache and pulsatile tinnitus with normal ICP (and without papilledema) could be considered as benign stages of IIH. In order to avoid semantic misunderstandings and to better encompass all the stages of $\mathrm{IIH}$, it is likely that the Dandy's criteria need to be updated, and that a rename of IIH has to be considered. 


\section{REFERENCES}

1 Lenck S, Radovanovic I, Nicholson P, Hodaie M, Krings T, Mendes-Pereira V: Idiopathic intracranial hypertension: The veno glymphatic connections. Neurology 2018;91:515-522.

2 Bezerra MLS, Ferreira A, de Oliveira-Souza R: Pseudotumor Cerebri and Glymphatic Dysfunction. Front Neurol 2017;8:734.

3 Iliff JJ, Wang M, Liao Y, Plogg BA, Peng W, Gundersen GA, Benveniste H, Vates GE, Deane R, Goldman SA, Nagelhus EA, Nedergaard M: A paravascular pathway facilitates CSF flow through the brain parenchyma and the clearance of interstitial solutes, including amyloid beta. Sci Transl Med 2012;4:147ra111.

4 Benveniste H, Lee H, Volkow ND: The Glymphatic Pathway. Neuroscientist 2017:1073858417691030.

5 Jessen NA, Munk AS, Lundgaard I, Nedergaard M: The Glymphatic System: A Beginner's Guide. Neurochem Res 2015;40:2583-2599.

6 Iliff JJ, Wang M, Zeppenfeld DM, Venkataraman A, Plog BA, Liao Y, Deane R, Nedergaard M: Cerebral arterial pulsation drives paravascular CSF-interstitial fluid exchange in the murine brain. J Neurosci 2013;33:18190-18199.

7 Keep RF, Jones HC: A morphometric study on the development of the lateral ventricle choroid plexus, choroid plexus capillaries and ventricular ependyma in the rat. Brain Res Dev Brain Res 1990;56:47-53.

8 Johanson CE, Duncan JA, 3rd, Klinge PM, Brinker T, Stopa EG, Silverberg GD: Multiplicity of cerebrospinal fluid functions: New challenges in health and disease. Cerebrospinal Fluid Res 2008;5:10.

9 Praetorius J: Water and solute secretion by the choroid plexus. Pflugers Arch 2007;454:1-18.

10 Koh L, Zakharov A, Johnston M: Integration of the subarachnoid space and lymphatics: is it time to embrace a new concept of cerebrospinal fluid absorption? Cerebrospinal Fluid Res 2005;2:6.

11 Cooper ER: Arachnoid granulations in man. Acta Anat (Basel) 1958;34:187-200.

12 Tsutsumi S, Ono H, Yasumoto Y: Pile driving into the skull and suspending the bridging veins? An undescribed role of arachnoid granulations. Surg Radiol Anat 2017;39:541-545.

13 Gailloud P, Muster M, Khaw N, Martin JB, Murphy KJ, Fasel JH, Rufenacht DA: Anatomic relationship between arachnoid granulations in the transverse sinus and the termination of the vein of Labbe: an angiographic study. Neuroradiology 2001;43:139-143.

14 Sandrone S, Moreno-Zambrano D, Kipnis J, van Gijn J: A (delayed) history of the brain lymphatic system. Nature medicine 2019;25:538-540.

15 Aspelund A, Antila S, Proulx ST, Karlsen TV, Karaman S, Detmar M, Wiig H, Alitalo K: A dural lymphatic vascular system that drains brain interstitial fluid and macromolecules. J Exp Med 2015;212:991-999.

16 Louveau A, Smirnov I, Keyes TJ, Eccles JD, Rouhani SJ, Peske JD, Derecki NC, Castle D, Mandell JW, Lee KS, Harris TH, Kipnis J: Structural and functional features of central nervous system lymphatic vessels. Nature 2015;523:337-341.

17 Absinta M, Ha SK, Nair G, Sati P, Luciano NJ, Palisoc M, Louveau A, Zaghloul KA, Pittaluga S, Kipnis J, Reich DS: Human and nonhuman primate meninges harbor lymphatic vessels that can be visualized noninvasively by MRI. Elife 2017;6 
18 Iliff JJ, Goldman SA, Nedergaard M: Implications of the discovery of brain lymphatic pathways. Lancet Neurol 2015;14:977-979.

19 Weller RO, Djuanda E, Yow HY, Carare RO: Lymphatic drainage of the brain and the pathophysiology of neurological disease. Acta Neuropathol 2009;117:1-14.

20 Reid AC, Matheson MS, Teasdale G: Volume of the ventricles in benign intracranial hypertension. Lancet 1980;2:7-8.

21 Alperin N, Ranganathan S, Bagci AM, Adams DJ, Ertl-Wagner B, Saraf-Lavi E, Sklar EM, Lam BL: MRI evidence of impaired CSF homeostasis in obesity-associated idiopathic intracranial hypertension. AJNR Am J Neuroradiol 2013;34:29-34.

22 Bidot S, Saindane AM, Peragallo JH, Bruce BB, Newman NJ, Biousse V: Brain Imaging in Idiopathic Intracranial Hypertension. J Neuroophthalmol 2015;35:400-411.

23 Maralani PJ, Hassanlou M, Torres C, Chakraborty S, Kingstone M, Patel V, Zackon D, Bussiere M: Accuracy of brain imaging in the diagnosis of idiopathic intracranial hypertension. Clin Radiol 2012;67:656-663.

24 Perez MA, Bialer OY, Bruce BB, Newman NJ, Biousse V: Primary spontaneous cerebrospinal fluid leaks and idiopathic intracranial hypertension. J Neuroophthalmol 2013;33:330-337.

25 Butros SR, Goncalves LF, Thompson D, Agarwal A, Lee HK: Imaging features of idiopathic intracranial hypertension, including a new finding: widening of the foramen ovale. Acta Radiol 2012;53:682-688.

26 San Millan D, Kohler R: Enlarged CSF spaces in pseudotumor cerebri. AJR Am J Roentgenol 2014;203:W457-458.

27 Bialer OY, Rueda MP, Bruce BB, Newman NJ, Biousse V, Saindane AM: Meningoceles in idiopathic intracranial hypertension. AJR Am J Roentgenol 2014;202:608-613.

28 Farb RI, Vanek I, Scott JN, Mikulis DJ, Willinsky RA, Tomlinson G, terBrugge KG:

Idiopathic intracranial hypertension: the prevalence and morphology of sinovenous stenosis. Neurology 2003;60:1418-1424.

29 Lenck S, Vallee F, Labeyrie MA, Touitou V, Saint-Maurice JP, Guillonnet A, Tantot A, Crassard I, Bernat AL, Houdart E: Stenting of the Lateral Sinus in Idiopathic Intracranial Hypertension According to the Type of Stenosis. Neurosurgery 2017;80:393-400.

30 Leach JL, Jones BV, Tomsick TA, Stewart CA, Balko MG: Normal appearance of arachnoid granulations on contrast-enhanced $C T$ and MR of the brain: differentiation from dural sinus disease. AJNR Am J Neuroradiol 1996;17:1523-1532.

31 Baryshnik DB, Farb RI: Changes in the appearance of venous sinuses after treatment of disordered intracranial pressure. Neurology 2004;62:1445-1446.

32 Kumpe DA, Bennett JL, Seinfeld J, Pelak VS, Chawla A, Tierney M: Dural sinus stent placement for idiopathic intracranial hypertension. J Neurosurg 2012;116:538-548.

33 De Simone R, Ranieri A, Sansone M, Marano E, Russo CV, Saccà F, Bonavita V: Dural sinus collapsibility, idiopathic intracranial hypertension, and the pathogenesis of chronic migraine. Neurological Sciences 2019;40:59-70.

34 De Simone R, Ranieri A, Montella S, Erro R, Fiorillo C, Bonavita V: Sinus venous stenosis-associated IIHWOP is a powerful risk factor for progression and refractoriness of pain in primary headache patients: a review of supporting evidences. Neurol Sci 2011;32 Suppl 1:S169-171. 


\section{FIGURE LEGENDS}

Figure 1 : The cascade of Idiopathic Intracranial Hypertension (IIHWOP: idiopathic intracranial hypertension without papilledema, IIH: idiopathic intracranial hypertension, ICP: intracranial pressure)

Figure 2: Radiological signs of Idiopathic Intracranial Hypertension. Figure 1A and 1B: T2weighted MRI in coronal view showing the excess CSF along the sheaths of the optic nerves (Fig. 1A, blue arrows) and of the IIIrd cranial nerves (Fig. 2B, blue arrows), a petrous apex meningocele (Fig. 2B, green arrow) and the CSF leak across the cribriform plate (Fig. 2A, yellow arrows). Figure 2C: CT scan in bone window showing the erosion of the cribriform plate (green arrow). Figure 2D: MR venography showing the bilateral transverse sinus stenoses (red arrows). 


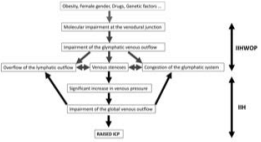


A

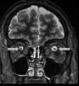

c

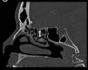

요

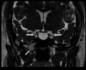

D
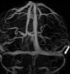